\title{
Augmented chemosensitivity to hypercapnia: another link in our understanding of the pathogenesis of Cheyne-Stokes respiration
}

\author{
P.J. Hanly
}

Since the original description of Cheyne-Stokes respiration (CSR) almost 180 yrs ago [1, 2] this form of central sleep apnoea (CSA) has remained the classic respiratory manifestation of severe congestive heart failure (CHF). In addition to recognizing CSR at the bedside, there have been many studies of its pathophysiology [3, 4]. Over the past $10 \mathrm{yrs}$, the extension of overnight polysomnography to patients with $\mathrm{CHF}$ has generated renewed interest in the pathogenesis of CSR, and its potential to cause sleep disruption, impairment of daytime function, and exacerbation of left ventricular dysfunction.

CSR is common in patients with CHF and has been estimated to occur in $40-50 \%$ of those with significant impairment of left ventricular function (ejection fraction $<45 \%$ ) [5]. Although CSR can occur during wakefulness, it is typically found during nonrapid eye movement (NREM) sleep [6]. Central apnoeas alternate with episodes of hyperpnoea with a classic crescendo/decrescendo appearance that reflects the periodic variation in central respiratory drive. Apnoeas are associated with intermittent hypoxaemia and hyperpnoeas are associated with arousals from sleep that typically occur at the peak of respiratory effort [6]. This fragmentation of sleep leads to excessive daytime sleepiness, which has been observed in patients with $\mathrm{CHF}$ and CSR in contrast to heart failure patients without CSR whose daytime alertness was similar to a healthy control group [7]. Unlike patients with obstructive sleep apnoea, excessive daytime sleepiness may be less obvious in patients with CSR due to co-existing symptoms from $\mathrm{CHF}$ and the effects of multiple cardiac medications.

CSR has also been associated with a higher mortality in patients with CHF [8]. Although this may simply reflect the fact that CSR is a marker of poor ventricular function, a more intriguing possibility is that CSR accelerates the deterioration in cardiac function by augmenting sympathetic nervous system activity (SNA) which has been correlated with increased mortality in CHF [9]. This is supported by reports that apnoea, hypoxaemia and sleep fragmentation, all of which occur during CSR, increase SNA in normal subjects $[10,11]$. Consequently, the role of CSR in clinical medicine has changed from that of an interesting physical sign to one with the potential to increase the morbidity and mortality of patients with CHF. Interestingly, many of the studies that have investigated the natural history of $\mathrm{CHF}$ and the impact of pharmacological interventions on clinical outcome have ignored the potential influence of CSR on their results $[12,13]$.

Correspondence: P.J. Hanly, Wellesley Central Hospital, 160 Wellesley St. E, Suite 247 Jones Building, Toronto, M4Y 1J3, Canada. Fax: 0014169265178
The possible influence of CSR on the natural history of $\mathrm{CHF}$ makes our understanding of its pathogenesis all the more important. The paper by WiLcox et al. [14] in this issue of the Journal provides important information in this regard. The pathogenesis of CSR is multifactorial and includes alteration of central respiratory control during transition from wakefulness to NREM sleep, hypocapnia, hypoxaemia (primarily through its effects on arterial carbon dioxide tension $\left.\left(\mathrm{Pa}_{\mathrm{a}} \mathrm{CO}_{2}\right)\right)$ and circulatory delay between the lung and carotid body [15]. Some patients with CHF hyperventilate while awake [16, 17], resulting in hypocapnia, which predisposes them to develop CSR during NREM sleep when breathing is primarily driven by $P \mathrm{a}, \mathrm{CO}_{2}$. Periodic oscillation of $\mathrm{Pa}, \mathrm{CO}_{2}$ above and below the critical level required to generate central respiratory rhythm (the so-called apnoea threshold [18]) results in CSR. This phenomenon may explain why only a proportion of patients with severe CHF develop CSR. Among a group of heart failure patients with otherwise identical cardiorespiratory profiles, only those with daytime hypocapnia developed CSR during sleep [17].

Why do some patients with CHF hyperventilate and others do not? Such patients are likely to experience increased pulmonary afferent stimulation from interstitial pulmonary oedema and hypoxia which may secondarily increase central hypercapneic drive. Alternatively, patients with a pre-morbid elevation of hypercapneic drive may "over-react" to relatively normal pulmonary afferent stimulation. Although the paper by WILCOx et al. [14] does not distinguish these two possibilities, it does highlight the importance of augmented hypercapneic drive in the pathogenesis of CSR which has also been described in patients with idiopathic CSA [19].

The report may also explain the gender difference in the prevalence of CSR. It is remarkable how few women have been found to have CSR, which has been a consistent and long-standing feature of clinical reports in this area $[3,4$, $6,8,16,20]$. The ventilatory responses both to hypoxia and hypercapnia are lower in women than men [21] which makes them less likely to hyperventilate and become hypocapneic. Assuming that hypocapnia is the final common pathway for the development of CSR, these lower ventilatory responses may "protect" women from developing CSR during sleep.

If Cheyne-Stokes respiration is associated with significant morbidity and mortality, it is important that we develop effective treatment strategies to minimize these complications. Current therapeutic options include supplemental oxygen [20], nasal continuous positive airway pressure [22], inhaled carbon dioxide, which has been used experimentally 
[23], and drugs such as theophylline [24]. The report by WiLcox et al. [14] improves our understanding of how existing treatments work and provides the basis for the development of new ones which may be more effective. Such studies are vital to understand the pathogenesis of Cheyne-Stokes respiration, to identify its role in the morbidity and mortality associated with congestive heart-failure and develop new and effective therapies.

\section{References}

1. Cheyne J. A case of apoplexy, in which the fleshy part of the heart was converted into fat. Dublin Hospital Reports 1818; 2: 216-223.

2. Stokes W. The Diseases of the Heart and Aorta. Dublin, Hodges and Smith, 1854; pp. 302-337.

3. Harrison TR, King CE, Calhoun JA, Harrison WG. Congestive heart failure: Cheyne-Stokes respiration as the cause of paroxysmal dyspnoea at the onset of sleep. Arch Int Med 1934: 53: 891-910.

4. Dowell AR, Buckley CE, Cohen R, Whalen RE, Sieker HO, Durham NC. Cheyne-Stokes respiration: a review of clinical manifestations and critique of physiological mechanisms. Arch Med 1971; 31: 277-281.

5. Javaheri S, Parker TJ, Wexler L, et al. Occult sleep-disordered breathing in stable congestive heart failure. Ann Int Med 1995; 122: 487-492.

6. Hanly PJ, Millar PW, Steljes PG, Baert R, Frais MA, Kryger MH. Respiration and abnormal sleep in patients with congestive heart failure. Chest 1989; 96: 480-488.

7. Hanly PJ, Zuberi N. Daytime sleepiness in patients with congestive heart failure and Cheyne-Stokes respiration. Chest 1995; 107: 952-958.

8. Hanly PJ, Zuberi-Khokhar N. Increased mortality associated with Cheyne-Stokes respiration in patients with congestivate heart failure. Am J Respir Crit Care Med 1996; 153: 272-276.

9. Cohn JN, Levine TB, Olivari MT, et al. Plasma norepinephrine as a guide to prognosis in patients with chronic congestive heart failure. N Engl J Med 1984; 311: 819823.

10. Somers VK, Dyken ME, Mark AL, Abboud FM. Sympathetic nerve activity during sleep in normal subjects. $N$ Engl J Med 1993; 328: 303-307.

11. Somers VK, Mark AL, Zavala DC, Abboud FM. Contrasting effects of hypoxia and hypercapnia on ventilation and sympathetic activity in humans. J Appl Physiol 1989; 67: 2101-2106.
12. Gradman AH, Deedwania PC. Predictors of mortality in patients with heart failure. Cardiol Clin 1994; 12: 2535.

13. Swedberg K, Eneroth P, Kjekshus J, Wilhelmsen L, for the CON-SENSUS Trial Study Group. Hormones regulating cardiovascular function in patients with severe congestive heart failure and their relation to mortality. Circulation 1990; 82: 1730-1736.

14. Wilcox, I, McNamara SG, Dodd MJ, Sullivan CE. Ventilatory control in patients with sleep apnea and left ventricular dysfunction: comparison of obstructive and central sleep apnea. Eur Respir J 1998; 11: 7-13.

15. Hanly PJ. Mechanisms and management of central sleep apnea. Lung 1992: 170: 1-17.

16. Naughton M, Benard D, Tam A, Rutherford R, Bradley TD. Role of hyperventilation in the pathogenesis of central sleep apneas in patients with congestive heart failure. Am Rev Respir Dis 1993; 148: 330-338.

17. Hanly PJ, Zuberi N, Gray R. Pathogenesis of CheyneStokes respiration in patients with congestive heart failure: relationship to arterial $\mathrm{PCO}_{2}$. Chest 1993; 104: 10791084.

18. Skatrud JB, Dempsey JA. Interaction of sleep state and chemical stimuli in sustaining rhythmatic ventilation. $J$ Appl Physiol 1983; 55: 813-822.

19. Xie A, Rutherford R, Rankin F, Wong B, Bradley TD. Hypocapnia and increased ventilatory responsiveness in patients with idiopathic central sleep apnea. Am J Respir Crit Care Med 1995; 152: 1950-1955.

20. Hanly PJ, Millar PW, Steljes DG, Baert R, Frais MA, Kryger MH. The effect of oxygen on respiration and sleep in patients with congestive heart failure. Ann Int Med 1989; 111: 777-782.

21. White DP, Douglas NJ, Pickett CK, Weill JV, Zwillich CW. Sexual influence on the control of breathing. J Appl Physiol Respir Environ Exercise Physiol 1983; 54: 874879.

22. Naughton MT, Liu PP, Bernard DC, Goldstein RS, Bradley TD. Treatment of congestive heart failure and CheyneStokes respiration during sleep by continuous positive airway pressure. Am J Respir Crit Care Med 1995; 151: 92-97.

23. Steens RD, Millar TW, Su X, et al. Effect of inhaled 3\% $\mathrm{CO}_{2}$ on Cheyne-Stokes respiration in congestive heart failure. Sleep 1994; 17: 61-68.

24. Javaheri S, Parker TJ, Wexler L, Limming JD, Lindower P, Roselle GA. Effect of theophylline on sleep-disordered breathing in heart failure. N Engl J Med 1996; 335: 562567. 